\title{
Numerical modelling of non-equilibrium condensation of carbon dioxide (CO2) in a converging-diverging nozzle
}

Wen, Chuang; Zhu, Xiaowei; Yang, Yan; Ding, Hongbing; Yan, Yuying

Published in:

AIP Conference Proceedings

Link to article, DOI:

$10.1063 / 5.0027863$

Publication date:

2020

Document Version

Publisher's PDF, also known as Version of record

Link back to DTU Orbit

Citation (APA):

Wen, C., Zhu, X., Yang, Y., Ding, H., \& Yan, Y. (2020). Numerical modelling of non-equilibrium condensation of carbon dioxide (CO2) in a converging-diverging nozzle. AIP Conference Proceedings, 2293(1), [420077 ]. https://doi.org/10.1063/5.0027863

\section{General rights}

Copyright and moral rights for the publications made accessible in the public portal are retained by the authors and/or other copyright owners and it is a condition of accessing publications that users recognise and abide by the legal requirements associated with these rights.

- Users may download and print one copy of any publication from the public portal for the purpose of private study or research.

- You may not further distribute the material or use it for any profit-making activity or commercial gain

- You may freely distribute the URL identifying the publication in the public portal 


\section{Numerical modelling of non-equilibrium condensation of carbon dioxide $\left(\mathrm{CO}_{2}\right)$ in a converging-diverging nozzle}

Cite as: AIP Conference Proceedings 2293, 420077 (2020); https://doi.org/10.1063/5.0027863 Published Online: 25 November 2020

Chuang Wen, Xiaowei Zhu, Yan Yang, Hongbing Ding, and Yuying Yan
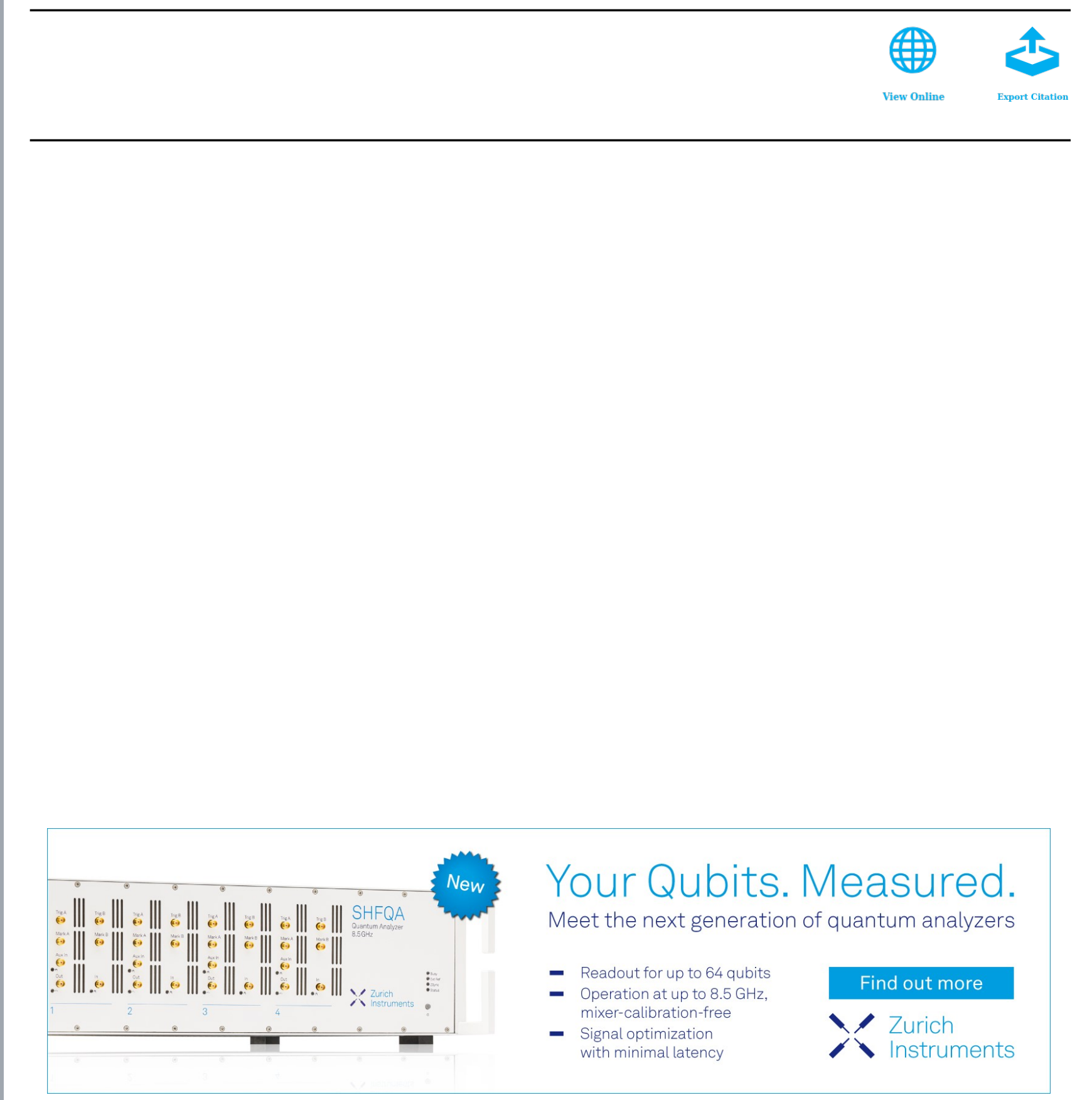


\title{
Numerical Modelling of Non-equilibrium Condensation of Carbon Dioxide $\left(\mathrm{CO}_{2}\right)$ in a Converging-diverging Nozzle
}

\author{
Chuang Wen ${ }^{1, \text { a) }}$, Xiaowei Zhu², Yan Yang ${ }^{2}$, Hongbing Ding ${ }^{3}$ and Yuying Yan ${ }^{1,4, b)}$ \\ ${ }^{1}$ Faculty of Engineering, University of Nottingham, University Park, Nottingham NG7 2RD, UK \\ ${ }^{2}$ Department of Mechanical Engineering, Technical University of Denmark, Nils Koppels Allé, 2800 Kgs. Lyngby, \\ Denmark \\ ${ }^{3}$ Tianjin Key Laboratory of Process Measurement and Control, School of Electrical and Information Engineering, \\ Tianjin University, Tianjin 300072, China \\ ${ }^{4}$ Center for Fluids \& Thermal Engineering, University of Nottingham Ningbo, China \\ b) Corresponding author: Yuying.Yan@nottingham.ac.uk \\ a) Chuang.Wen@nottingham.ac.uk
}

\begin{abstract}
The condensing flow model is developed to predict the non-equilibrium condensation of $\mathrm{CO}_{2}$ in a convergingdiverging nozzle using computational fluid dynamics modelling, which is expected to contribute to the carbon capture and storage. The numerical result shows that the nucleation process of $\mathrm{CO}_{2}$ occurs in the downstream of the nozzle throat where the extremely non-equilibrium state is reached, which generates the maximum value of the nucleation rate of approximately $2.5 \times 10^{18} \mathrm{~m}^{-3} \mathrm{~s}^{-1}$. The excessive nucleation induces the growth of the condensed droplet and the liquid fraction increase in the diverging part of the supersonic nozzle with achieving $8 \%$ of the total mass at the nozzle exit.
\end{abstract}

\section{INTRODUCTION}

The concerns of environmental pollution and climate change require the clean utilization of fossil fuels to reduce the emission of carbon dioxide $\left(\mathrm{CO}_{2}\right)^{1}$. The separation of $\mathrm{CO}_{2}$ is one of the important steps for carbon capture and storage (CCS) technology, which provides a remarkable measure to mitigate emissions ${ }^{2}$. The conventional separation technologies, such as absorption, adsorption and membranes, show good performance on $\mathrm{CO}_{2}$ separation with some disadvantages including the large investment and the possibility of the chemicals.

The supersonic separation is introduced to remove the water vapour from wet natural gas, which is based on the non-equilibrium condensation in supersonic flows ${ }^{3}$. Both numerical and experimental studies have been carried out to evaluate the separation performance of water vapour inside a supersonic separator ${ }^{4,5}$. In this study, we develop a condensing flow model to predict the non-equilibrium condensation of $\mathrm{CO}_{2}$ in a converging-diverging nozzle using computational fluid dynamics modelling.

\section{NUMERICAL MODELLING}

The numerical modelling is developed based on following assumptions ${ }^{6}: 1$ ) the single-fluid model is used without considering the slip velocity between the vapour phase and liquid phase; 2) there is no temperature difference between the vapour and liquid phases; 3 ) the condensed droplets distributed uniformly in the vapour phase. The unsteady, compressible Navier-Stokes equations are employed to govern the fluid flow inside the converging-diverging nozzle. The governing equations are expressed as:

$$
\frac{\partial(H)}{\partial t}+\frac{\partial\left(U_{x}\right)}{\partial x}+\frac{\partial\left(U_{y}\right)}{\partial y}=\frac{\partial\left(J_{x}\right)}{\partial x}+\frac{\partial\left(J_{y}\right)}{\partial y}+S
$$


where

$$
\begin{gathered}
H=\left[\begin{array}{l}
\rho \\
\rho u \\
\rho v \\
\rho E \\
\rho \zeta \\
\rho N
\end{array}\right], U_{x}=\left[\begin{array}{l}
\rho u \\
\rho u u+p \\
\rho u v \\
\rho u(E+p) \\
\rho u \zeta \\
\rho u N
\end{array}\right], U_{y}=\left[\begin{array}{l}
\rho v \\
\rho v v+p \\
\rho v(E+p) \\
\rho v \zeta \\
\rho v N
\end{array}\right] \\
J_{x}=\left[\begin{array}{l}
0 \\
\tau_{x x} \\
\tau_{x y} \\
q_{x} \\
0 \\
0
\end{array}\right], J_{y}=\left[\begin{array}{l}
0 \\
\tau_{x y} \\
\tau_{y y} \\
q_{y} \\
0 \\
0
\end{array}\right], S=\left[\begin{array}{l}
-\dot{m} \\
-u \dot{m} \\
-v \dot{m} \\
-\left(h_{v}-h_{f g}\right) \dot{m} \\
\dot{m} \\
\rho I
\end{array}\right]
\end{gathered}
$$

where $H$ represents conservation variables, $U$ and $J$ are inviscid and viscid fluxes, $S$ is the source term. $\zeta$ and $N$ are the liquid fraction and droplet numbers. $\rho$ and $p$ are density and pressure. $E$ is the total energy, $u$ and $v$ are the velocity components. $I$ is the nucleation rate. $\dot{m}$ is the condensation mass per unit vapour volume per unit time ${ }^{7}$ :

$$
\begin{gathered}
\dot{m}=\frac{4 \pi r_{c}^{3}}{3} \rho_{l} I+4 \pi r^{2} \rho_{l} N \frac{d r}{d t} \\
I=\frac{q_{c}}{1+\phi} \frac{\rho_{v}^{2}}{\rho_{l}} \sqrt{\frac{2 \sigma}{\pi m_{v}{ }^{3}}} \exp \left(-\frac{4 \pi \sigma}{3 k_{B} T_{v}} r_{c}^{2}\right) \\
\frac{d r}{d t}=\frac{\lambda_{v}\left(T_{s}-T_{v}\right)}{\rho_{l} h_{l v} r} \frac{\left(1-r_{c} / r\right)}{\left(\frac{1}{1+2 \beta \mathrm{Kn}}+3.78(1-v) \frac{\mathrm{Kn}}{\mathrm{Pr}}\right)}
\end{gathered}
$$

where $\rho_{l}$ is the droplet density, $r$ is the droplet radius. $d r / d t$ is the growth rate of droplets ${ }^{8}$, and $r_{c}$ is critical droplet radius. $q_{c}$ is the condensation coefficient, $\sigma$ is the liquid surface tension, $m_{v}$ is the mass of a vapour molecule, $k_{B}$ is the Boltzmann's constant. $T_{v}$ is the vapour temperature. $\phi$ is a correction factor. $T_{s}$ is the saturated temperature, $\operatorname{Pr}$ is the Prandtl number, $\mathrm{Kn}$ is the Knudsen number and $v$ is the modelling correction coefficient.

\section{RESULTS AND DISCISSION}

The converging-diverging nozzle is used to model the non-equilibrium condensation of $\mathrm{CO}_{2}$ in supersonic flows. The diameters at the inlet, throat and outlet are $54.4 \mathrm{~mm}, 13.1 \mathrm{~mm}$ and $26.2 \mathrm{~mm}$, respectively. The structural grid is generated for the numerical simulation and 28480 cells are chosen based on the mesh independent test with 12000 cells, 28480 cells and 57600 cells. The detailed dimension and mesh generation are shown in Fig. 1.
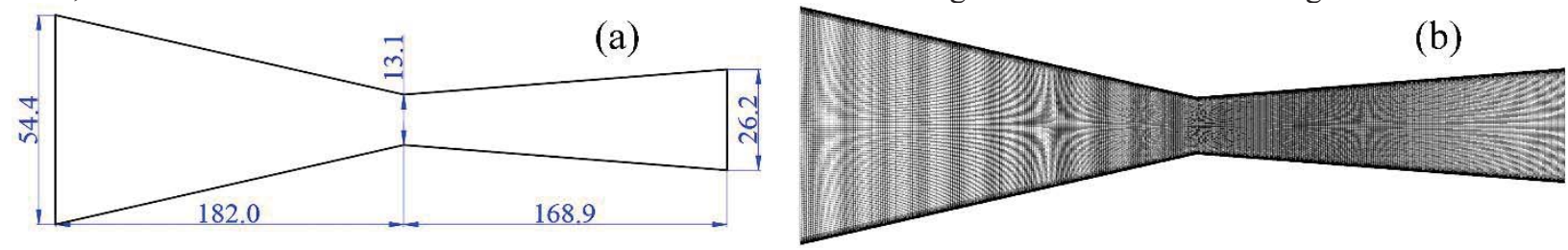

FIGURE 1. Geometry and structural mesh of the converging-diverging nozzle

Figure 2 shows the static pressure and Mach number of $\mathrm{CO}_{2}$ inside the converging-diverging nozzle during the non-equilibrium condensation process. It can be seen that $\mathrm{CO}_{2}$ accelerates in the converging part of the nozzle and reaches the critical state at the nozzle throat with the Mach number of unity. Then the supersonic flow is achieved in the diverging part with a Mach number of 1.87 at the exit plane of the nozzle. 
Figure 3 describes the distribution of the nucleation rate and liquid fraction inside the converging-diverging nozzle. It can be observed that the nucleation process occurs in the downstream of the nozzle throat with a maximum value of approximately $2.5 \times 10^{18} \mathrm{~m}^{-3} \mathrm{~s}^{-1}$. Combining with the static pressure and Mach number in Fig. 2, the profiles jump due to the release of the latent heat during the phase change in a non-equilibrium state. When looking at the details of the nucleation and liquid fraction, it can be observed that the onset of liquid fraction is in the downstream of the onset of nucleation which means that growth of the droplet follows the nucleation process. In this case, the liquid fraction can reach $8 \%$ of the total mass of the $\mathrm{CO}_{2}$.

In addition, the shock wave appears in the diverging part of the nozzle due to the existence of the sharp point at the nozzle throat. The shock wave not only influences the flow structure but also the phase change process, which results in the energy loss. It indicates that the effect of the nozzle geometry needs to be improved for efficient energy utilization.

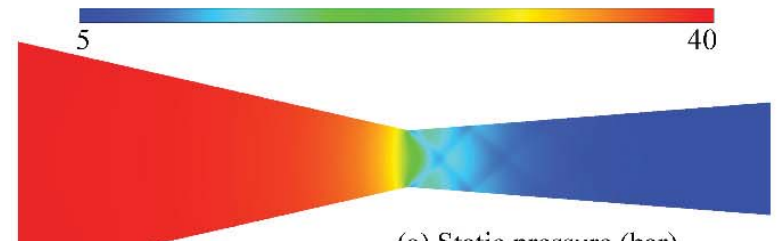

(a) Static pressure (bar)
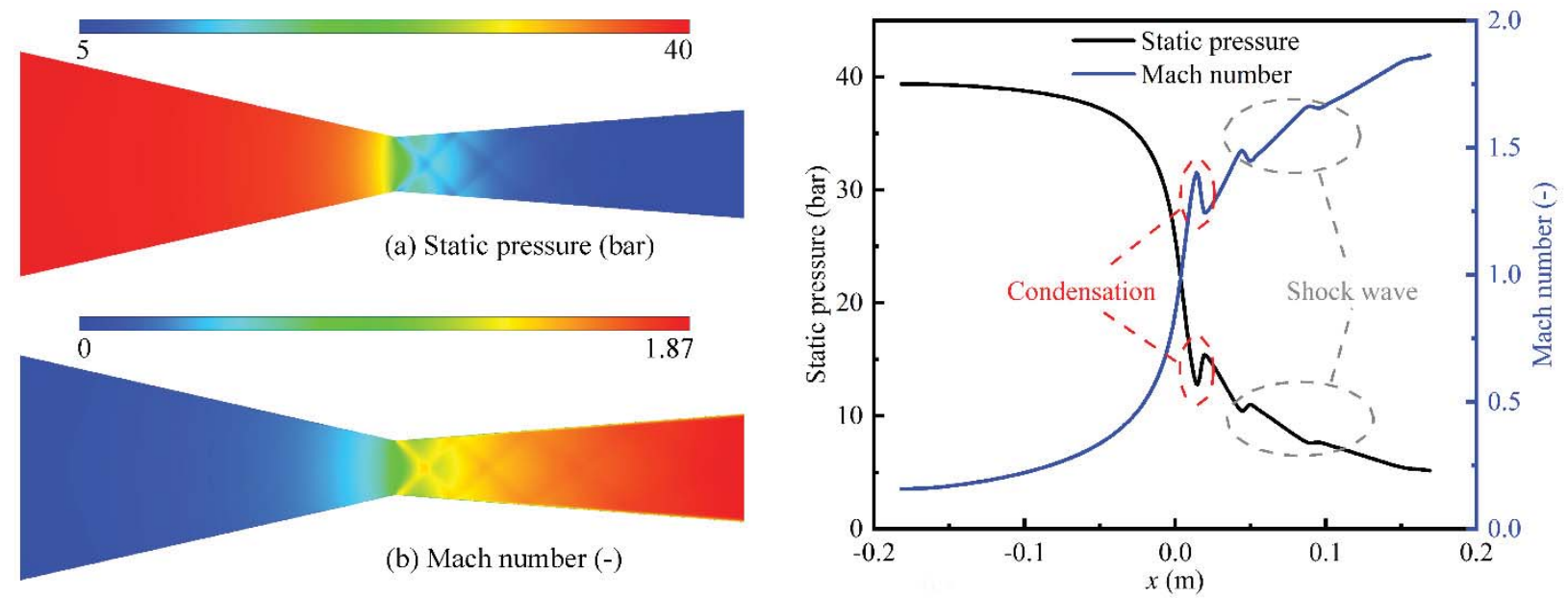

FIGURE 2. Static pressure and Mach number in the converging-diverging nozzle
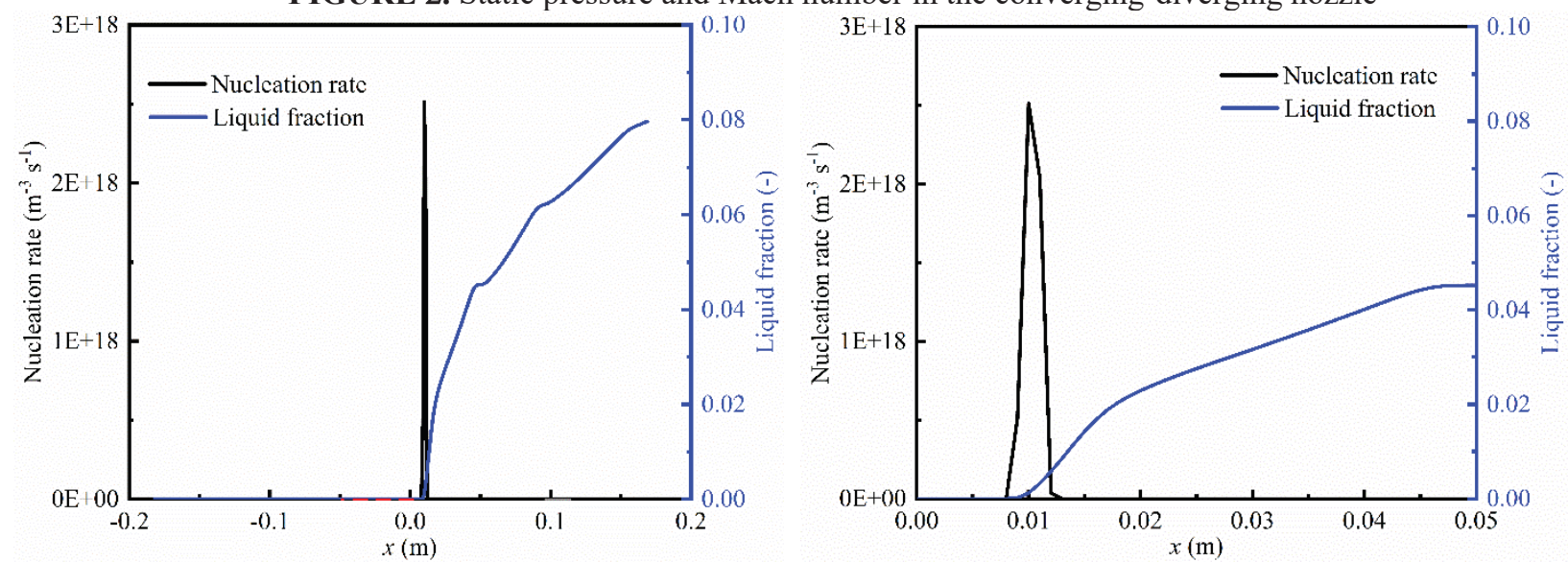

FIGURE 3. Nucleation rate and liquid fraction in the converging-diverging nozzle

\section{CONCLUSIONS}

The converging-diverging nozzle is used to study the non-equilibrium condensation of $\mathrm{CO}_{2}$ in supersonic flows, which can be used to reduce the carbon emission and contribute to the carbon capture and storage. The numerical simulation demonstrates that the nucleation occurs in the downstream of the nozzle throat and liquid fraction can achieve $8 \%$ of the total mass in this simulation case. 


\section{ACKNOWLEDGEMENTS}

This project has received funding from the European Union's Horizon 2020 research and innovation programme under the Marie Sklodowska-Curie grant agreement No 792876 and No 778104.

\section{REFERENCES}

1. S. Sgouridis, M. Carbajales-Dale, D. Csala, M. Chiesa and U. Bardi, Nat. Energy 4 (6), 456 (2019).

2. C. Wen, N. Karvounis, J. H. Walther, Y. Yan, Y. Feng and Y. Yang, Appl. Energy 238, 311-319 (2019).

3. Y. Yang, C. Wen, S. Wang and Y. Feng, Appl. Energy 132, 248-253 (2014).

4. S. F. Interlenghi, F. S. Raquel de Pádua, J. L. de Medeiros and O. d. Q. F. Araújo, Energy Convers. Manage. 195, 1334-1349 (2019).

5. Y. Yang and C. Wen, Sep. Purif. Technol. 174, 22-28 (2017).

6. Y. Yang, X. Zhu, Y. Yan, H. Ding and C. Wen, Appl. Energy 242, 157-167 (2019).

7. Y. Yang, J. H. Walther, Y. Yan and C. Wen, Appl. Therm. Eng. 115, 1357-1362 (2017).

8. J. Young, Phys. Chem. Hydrodyn. 3 (1), 57-82 (1982). 